\title{
Klingler's method of brain dissection: review of the technique including its usefulness in practical neuroanatomy teaching, neurosurgery and neuroimaging
}

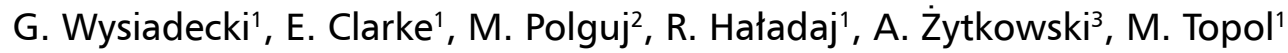 \\ ${ }^{1}$ Department of Normal and Clinical Anatomy, Interfaculty Chair of Anatomy and Histology, \\ Medical University of Lodz, Poland \\ 2Department of Angiology, Interfaculty Chair of Anatomy and Histology, Medical University of Lodz, Poland \\ ${ }^{3}$ Department of Biomechanics and Prosthetic-Orthopaedic Supply, Medical University of Lodz, Poland
}

[Received: 14 August 2018; Accepted: 14 September 2018]

\begin{abstract}
Klingler's technique was discovered in the 1930s. It is a modified method of brain fixation and dissection, based on freezing and thawing of the brain tissue, subsequent peeling away of white matter fibres and the gradual exposure of white matter tracts. The added value of this technique is that it is carried out in a stratigraphic manner. This fact makes it an invaluable tool for an in-depth understanding of the complex anatomical organisation of the cerebral hemispheres. The purpose of this paper is to provide a review of Klingler's method while taking into account the original description of the technique and its value for medical training. The historical background, the concise outline of white matter organisation, as well as our own experience in using this procedure for research and teaching activities were also included.

The fibre dissection technique may still be considered an excellent complementary research tool for neuroanatomical studies. Numerous detailed observations about the white matter topography and spatial organisation have been recently made by applying this method. Using this technique may also improve understanding of the three-dimensional intrinsic structure of the brain, which is particularly important both in under- and postgraduate training in the field of neuroanatomy. (Folia Morphol 2019; 78, 3: 455-466)
\end{abstract}

Key words: fibre dissection technique, Klingler's technique, neuroanatomy, white matter, tractography

\section{INTRODUCTION}

"The dissection of the human brain is a rewarding experience for both teachers and students if it proceeds in a systematic fashion" - this statement taken from the Heimer's textbook of neuroanatomy [23] seems to be a fitting motto for our review. However, exploration of the complex spatial relations between grey and white matter may be both fascinating and challenging. Difficulties may be faced especially by medical students who study the internal structure of the brain based mainly on two-dimensional (2D) sections. The understanding of the orientation and topography of nuclei and fibre tracts through the study of the sectional anatomy of the central nerv-

Address for correspondence: Dr. G. Wysiadecki, Department of Normal and Clinical Anatomy, Interfaculty Chair of Anatomy and Histology, Medical University of Lodz, ul. Żeligowskiego 7/9, 90-752 tódź, Poland, e-mail: grzegorz.wysiadecki@umed.lodz.pl 
ous system needs much effort $[32,46]$. This type of exposing of the brain's anatomy has a long tradition. Performing a series of appropriately conducted cuts through the brain appears to be the primary method of dissection of this organ, which may be confirmed by the analysis of leading anatomical works beginning with De humani corporis fabrica by Vesalius [56] as well as in most of the excellent modern atlases of human anatomy. However, progress which is taking place in the field of clinical disciplines, such as diagnostic imaging or neurosurgery as a specific example, requires the need of advanced knowledge regarding the organisation of the grey and white matter, as well as specific connectivity patterns in the three-dimensional (3D) brain space $[1-6,24,27$, $30,38,42,50,60]$.

The nature of the body is 3D; thus, it is not surprising as Poliakov et al. [41] emphasized, that 3D imaging has become an integral part of biomedicine. New and previously unknown pathways were discovered with the use of diffusion imaging methods [41]. The causative effects of altered white matter anatomy in cognitive and behavioural disorders are becoming more evident, which may also help to predict abnormal brain states $[7,25,48,64]$. At the same time, some data are suggesting that students perceive neuroanatomy as a complicated topic $[8,26]$. Even special terms such as "neurophobia" were introduced by Józefowicz [26], to express students' fear of the neural sciences and clinical neurology. Therefore, appropriate teaching methods and tools in neuroanatomy have become more critical than ever before. Chang and Molnár [8] indicate that neuroanatomy meets the criteria of an ideal preclinical subject due to the beauty of the nervous system, the logic of most of its pathways and clinic-anatomical correlations. According to those authors, the dissection or inspection of the human brain is one of the teaching methods that allow students to learn anatomy in detail, including normal variations. A thorough understanding of the underlying organisational principles of the brain can help students, as well as practitioners, better prepare for the use of advanced diagnostic and invasive procedures within the central nervous system $[3,18,33,47]$.

Klingler's technique was first discovered in the 1930s. It is a modified method of the brain fixation and dissection, based on freezing and thawing of the brain tissue, subsequent peeling away white matter fibres and the gradual exposure of white mat- ter tracts [32]. The added value of this technique is that it is carried out in a stratigraphic manner. This fact makes it an invaluable tool for in-depth understanding of complex anatomic organisation of the cerebral hemispheres $[14,53]$. The purpose of this paper is to provide a review of the Klingler method, taking into account the original description of the technique and its value for medical training. The historical background, the concise outline of white matter organisation, as well as our own experience in using this procedure for research and teaching activities were also included.

\section{HISTORICAL PERSPECTIVE}

Anatomy is one of the oldest disciplines of medicine. Knowledge about construction and the functioning of the human body has been acquired gradually over the centuries, with great difficulty, and its beginnings are derived from the most straightforward, often accidental, observations made on human and animal organisms. The origin of knowledge about the brain derived from the ancient world and began to emerge among philosophical considerations, myths, and metaphors. The first documented mention of the brain occurs in the Edwin Smith surgical papyrus, in the description of a person with a skull fracture (case 6 out of 48 cases described in this ancient document) [20]. The Edwin Smith papyrus is an ancient Egyptian medical text dated to about $1700 \mathrm{BC}$. It also contains notes on the relationship between laterality of the injury and laterality of the observed deficits and symptoms [20]. However, the brain was not always considered the chief organ of the human body: the habitat of thoughts, feelings, and identity. In ancient Egypt, the brain was considered a habitat of temptation and demons, and the heart was considered the seat of the soul [39]. According to Aristotle, the brain was a cooling organ, while Hippocrates saw it as the source of phlegm [20].

At the beginning of the Renaissance Scientific Revolution, the distinction was not made between grey and white matter. In those times, exploring the interior of the skull was subordinated to the search for the location of the soul or sensus communis - the power of the mind integrating information received through the senses and ultimately leading to judgements and decisions. In this context, the investigations of the pioneers of anatomy were directed to an accurate description of the brain's chambers. The treatise Isagogae Breves ("A short introduction to anatomy") 


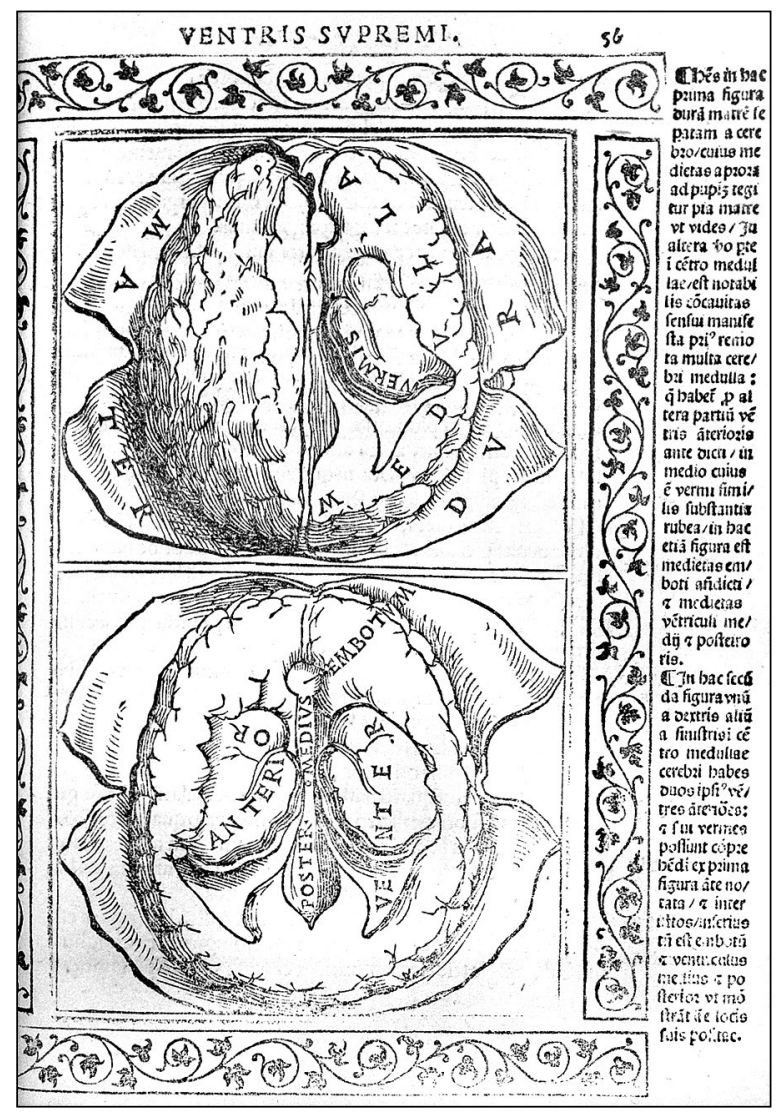

Figure 1. The first known engraving, whose primary motive is the brain and which was made "from nature". Original work: Jacopo Berengarius da Carpi (1523) Isagoge breves. Benedictus Hector, Bologna [11]. Credit: Wellcome Collection, https://wellcomecollection.org/works/bcydgft3. Licence: Creative Commons Attribution (CC BY 4.0): https://creativecommons.org/licenses/by/4.0.

by Jacopo Berengario da Carpi [11] contains the first known engraving, which the main subject was the brain, and which was made "from nature" (Fig. 1) [49]. In times contemporary to Berengario, the brain functions were associated with the ventricular system (Vesalius first introduced the term ventriculus), while the cerebral tissue was attributed only to the supporting function $[19,49]$. Archiangelo Piccolomini (1526-1586), professor of anatomy in Rome, was the first who made a clear distinction between the cerebral cortex (which he called as "cerebrum") and white matter (which he described as "medulla") — he also separated the two parts during the dissection [20]. The role of ventricles and rete mirable, which were two basic structures in the Galenic concept of the brain, was questioned by Vesalius. Although Vesalius did not create a new theory on the functioning of the brain, it paved the way to a more realistic reflection of its structure, "both in words and in pictures" [19].

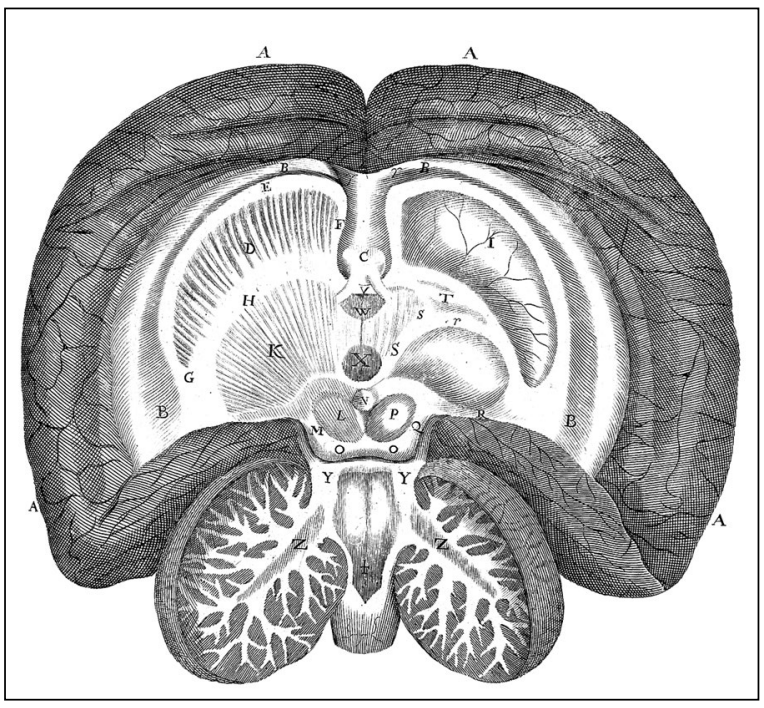

Figure 2. The dissection of the human brain showing corpus striatum, brain stem and cerebellum. The background of the original figure was changed to white. Original work: Thomas Willis (1684) VI. Of the anatomy of the brain. Printed for T. Dring, C. Harper, and J. Leigh, London [57]. Credit: Wellcome Collection, https://wellcomecollection.org/works/s4v4y48p. Licence: Creative Commons Attribution (CC BY 4.0): https://creativecommons.org/licenses/by/4.0.

Science has come a long way through the centuries in understanding the organisation and role of the white and grey matter. With the Cerebri anatome written by Thomas Willis (1621-1675) new anatomical terms, such as lobe, hemisphere, peduncle or corpus striatum, have been coined and introduced into use [19]. The debut of the treatise took place in 1664. A plate from one of the treatises of Willis, showing the dissection of the human brain, is presented in Figure 2 [57]. The $18^{\text {th }}$ century brought the development of knowledge over cortical localisation. During this period, it was hypothesized that the sizeable cerebral mass above the brainstem must be associated with higher functions, such as thinking, cognition, and perception. Pioneers in this field were Emanuel Swedenborg and Franz Joseph Gall, who observed that frontal lobes are associated with human's personality [19]. Gradually, an utterly erratic system of "cerebral convolutions," which looked like intestines on first anatomical plates, proceeded to transform into a precise map.

In contrast to the interest in the grey matter and the cerebral cortex, research regarding the detailed structure, arrangement, and organisation of the white matter appeared to lose its significance and relevance until the advent of modern neurosurgery in the $20^{\text {th }}$ century. However, many tracts and fasciculi 


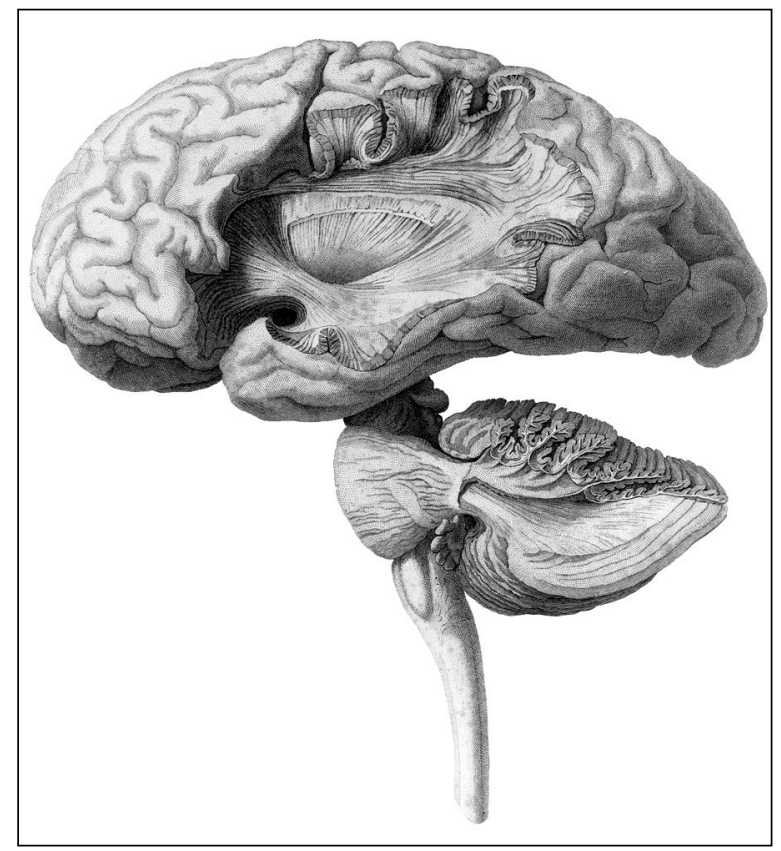

Figure 3. Drawing illustrating the dissection of the white matter fibres taken from Mayo's engravings. On this picture, white matter fibres where exposed by using the fibre dissection method similar to Klingler's technique. Superior longitudinal, inferior occipitofrontal and uncinate fasciculi are shown, as well as stratigraphic dissection of the extreme and external capsules. The original figure was cropped to better visualise the details of the drawing. The background was changed to white. Original work: Mayo HM (1827) A series of engravings intended to illustrate the structure of the brain and spinal cord in man. Burgess and Hill, London [34]. Credit: Wellcome Collection, https://wellcomecollection.org/works/jphtdgeh. Licence: Creative Commons Attribution (CC BY 4.0): https:// creativecommons.org/licenses/by/4.0.

were discovered by early pioneers in neuroanatomy. Elements of the fibre dissection technique were used already in the $17^{\text {th }}$ century by such anatomists as Thomas Willis or Nicolaus Steno (1638-1686) [53]. Raymond Vieussens (1635-1715) presented a detailed description of the fibre dissection in his treatise entitled Neurographia universalis. With regards to the white matter, the Vieussens used such terms as "medullary substance" or "medulla". He was aware of the fact that the medullary substance consists of "innumerable fibres" that are connected, whereby he observed this by boiling white matter in oil [53]. Vieussens observed continuity of the corona radiata, internal capsule, cerebral peduncle and pyramidal tracts within the pons and medulla oblongata. After more than a century break, the fibre dissection technique was rediscovered. During this period exquisite anatomical works were created, containing anatomical engravings of specimens prepared by use of fibre

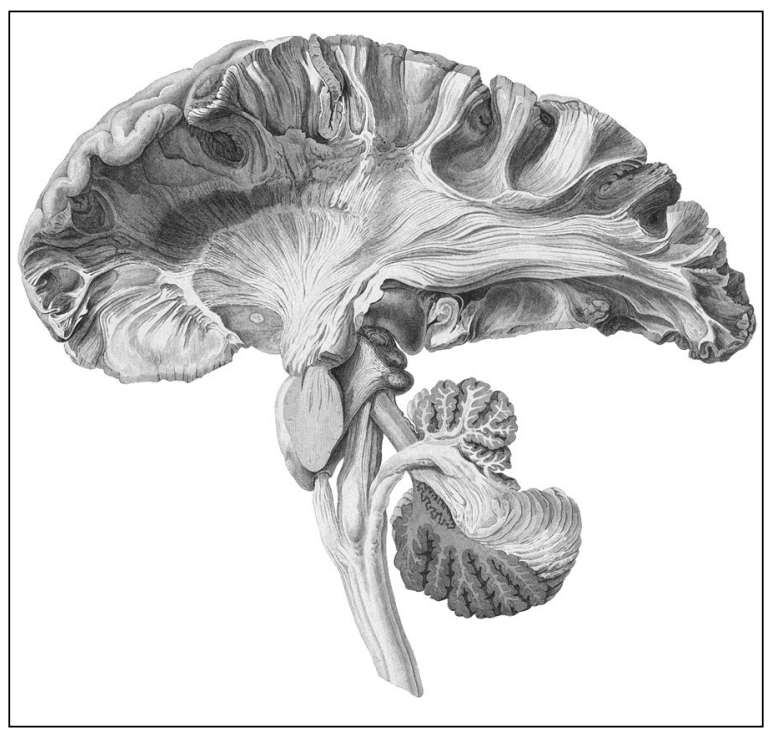

Figure 4. Drawing illustrating the dissection of the white matter fibres taken from Mayo's engravings. Deep dissection of the superolateral surface of the cerebral hemisphere. Corona radiata, internal capsule, cerebral crus and cerebellar peduncles were clearly exposed by using the fibre dissection method similar to Klingler's technique. The original figure was cropped to better visualise the details of the drawing. The background was changed to white. Original work: Mayo HM (1827) A series of engravings intended to illustrate the structure of the brain and spinal cord in man. Plate IV. Burgess and Hill, London [34]. Credit: Wellcome Collection, https://wellcomecollection.org/works/v4jynbs6. Licence: Creative Commons Attribution (CC BY 4.0): https://creativecommons.org/ licenses/by/4.0.

dissection technique, to give examples of works by such authors as Sir Charles Bell (1774-1842), Herbert Mayo (1796-1852), Friedrich Arnold (1803-1890) and Achille Louis Foville (1799-1878) [53]. Nineteenth-century anatomical plates, including those based on the fibre dissection technique, surprised in both artistic and scientific details of the then current knowledge of the anatomy of the brain (Figs. 3, 4) [34]. A list of selected researchers publishing in the $19^{\text {th }}$ century with the structures demonstrated by them in their works by using the fibre dissection technique is presented in Table 1.

At the beginning of the $20^{\text {th }}$ century, fibre dissection lost its significance in favour of histological techniques [32]. However, using the progress in technology, Joseph Klingler (1888-1963) improved fibre dissection technique. His main contribution to the development of this method consisted in the introduction of freezing the brain specimens prior to the procedure. Klingler based his method on the assumption that ice crystals precipitate between the 
Table 1. A list of selected researchers publishing in the $19^{\text {th }}$ century with the structures demonstrated by them in their works by using fibre dissection technique, based on the description by Türe et al. [53]

\begin{tabular}{ll}
\hline Researchers & Demonstrated structures \\
\hline Johann Christian Reil (1759-1813) & Tapetum, optic radiation \\
Franz Joseph Gall (1758-1828) and & $\begin{array}{l}\text { Definitive confirmation of the medullary decussation } \\
\text { of the pyramids }\end{array}$ \\
Johann Gaspar Spurzheim (1776-1832) & Corona radiata, internal capsule, superior and inferior cerebellar peduncles, \\
Herbert Mayo (1796-1852) & superior longitudinal fasciculus, uncinate fasciculus, tapetum, \\
& mammillothalamic tract, anterior commissure \\
Friedrich Arnold (1803-1890) & Frontopontine (Arnold's) tract \\
Karl Friedrich Burdach (1776-1847) & Cuneate fasciculus (of Burdach) \\
Bartholomeo Panizza (1785-1867) & Visual pathway from the eye to the occipital cortex \\
Louis Pierre Gariolet (1815-1865) & Optic radiation (Gariolet's radiation) \\
Theodor Hermann Meynert (1833-1892) & Fasciculus retroflexus (Meynert's bundle) \\
Joseph Jules Dejerine (1849-1917) & Occipitofrontal fasciculus \\
\hline
\end{tabular}

fibres of the white matter during freezing: "Since water increases 10 per cent in volume with the formation of ice, the fibres are somewhat spread apart. It is this loosening of the tissue, which not only makes following of fine fibre bundles easier but in fact, makes it possible at all." [32]. Histological and ultrastructural changes induced by Klingler's method was described by Zemmoura et al. in 2016 [63]. An electron microscopy study of frozen-defrosted human white matter revealed that the freezing and defrosting process created "extra-axonal lacunas" with the maintenance of axonal integrity [63], which confirms Klingler's assumptions.

The atlas which reproduced specimens obtained with the use of the freezing technique was presented at the International Congress in Milan, in 1936. The first edition of the atlas was released in 1938 [32]. The work was out of print in a short time. The complete demonstration of specimens prepared by Joseph Klingler and his colleagues was arranged at the International Congress of Anatomy which took place in Paris in 1955. The next edition of the Atlas cerebri humani by E. Ludwig and J. Klingler was released in 1956 [32]. This anatomical masterpiece was published by S. Karger, Basel, New York. The Atlas contains 100 black and white photographs of excellent quality. The descriptions are placed on schematic sketches. Klingler's preparations influenced neurologists, neurosurgeons, and neuroscientists. Thanks to the innovations in fibre dissection technique, the inner topography of the brain became clearer long before the invention of tractography - a computational reconstruction method which allows for revealing white matter pathways in vivo. In the context of neuroanatomical research, the fibre dissection technique is still improving. Classical fibre dissection technique, described by Klingler, consisted of removing the cortex and overlying white matter. Martino et al. [33] modified this methodology by introducing "cortex-sparing fibre dissection" that preserves the cortex and the relationships within the brain during all stages of dissection. This modified procedure enables the tracing of fibres to their terminations in the cortex.

\section{APPLICATION OF THE KLINGLER'S METHOD}

Our experiments with the Klingler's method of brain dissection were necessitated by the need for supplemental specimens for teaching purposes. Although we based the procedure on the original description of the method [32], the current reality of the anatomical laboratory forced some modifications. Differences resulted mainly from the limited availability of fresh brain specimens and were caused by the necessity of obtaining the brain from formalin-embalmed cadavers. Only three brains dissected in our department by Klingler's technique were harvested immediately post-mortem and fixed according to the original description of the procedure, through the basilar artery [32]. In the remaining 17 cases, access through the common carotid artery was performed for the needs of the embalming procedure. This change of fixation method does not seem to influence the success of the procedure. Moreover, Latini et al. [28] proved that intra-carotidal formalin 
perfusion fixation provides homogeneous and rapid fixation of the brain which allows for documentation of additional anatomical details (such as intra-cortical white matter terminations or even accumbo-frontal fasciculus). After embalming, the bodies, from which the brains were harvested, were stored in $10 \%$ formalin solution. The time from the fixation procedure to opening the skull and harvesting the brain varied from 6 months to 1 year for specimens used for our preparations. We did not notice any adverse effect due to the extended time from fixation to brain collection, which seems to be consistent with the observations made by Klingler, who stated that "Longer storage in $5 \%$ formol, up to a year or more, is beneficial rather than harmful" [32].

It should be noted that we paid particular attention to the method of opening the skull, which enabled the entire brain to be preserved in an intact state. To this end, we used the extended access to the skull described earlier by Long et al. [31]. This procedure was based on the additional removal of the wedge-shaped part of the occipital squama. This access not only protects the cranial nerves, which allows obtaining a good quality of specimens [21, $59,61]$ but also prevents accidental damage to the brainstem, which is crucial especially when using the Klingler's method. The access may be extended by removal of the vertebral arches (vertebral pedicles must be carefully chiseled), which allows obtaining a complete specimen of the brain and spinal cord. The brains obtained in this way were rinsed under cold running water and then placed in the plastic bag in the freezer for 1 week. Although attempts on unfrozen brains showed that, especially during classes, elements of the fibre dissection could be used to make a clear demonstration, only freezing allows for getting the best results by the described method. These observations are consistent with those of Türe et al. [53], who stated that the freezing process facilitates the dissection of fine fibre bundles. According to the original description of the technique [32], the brain, after 8 days of storage at the temperature of $-8^{\circ} \mathrm{C}$ to $-10^{\circ} \mathrm{C}$, should be thawed in running water. It is also important that after thawing, which takes approximately $24 \mathrm{~h}$ at room temperature, our specimens were dissected immediately. However, if it is necessary to divide the procedure into stages, $2-5 \%$ formalin solution should be used as a preservative fluid, according to original Klingler's description [32]. If the interval between subsequent stages of the fibre dissection has to be delayed for a long time (i.e., over 1 month), Türe et al. [53] recommends that the specimen should be frozen again, for at least $12 \mathrm{~h}$, and then thawed prior to the continuation of the procedure.

In this section, the basic techniques of fibre dissection are presented, exposing the most important structures and topographical relationships within the brain hemispheres. Examples of more advanced uses of Klingler's method will be briefly described in the next section of this review. The method does not require the use of complicated instruments. In addition to hand-made wooden spatulas of various sizes with rounded ends, delicate microsurgical tweezers with curved ends, as well as delicate probe with rounded edges, scalpel and magnifying equipment may also be useful. In further descriptions, the recent version of Terminologia Neuroanatomica will be used, based on the report of Ten Donkelaar et al. [51].

The dissection of the superolateral aspect of the cerebral hemisphere provides an excellent insight into the structure of the major fibre bundles. This type of exposure is also recommended for those who are taking their first attempts at fibre dissection. The cerebral cortex may be removed, to expose U-fibres (the short association fibres for which the old term arcuate fibres was used) or preserved intact, according to modification of Martino et al. [33]. Careful removal of the frontal, temporal, or parietal operculum reveals the insular cortex (Fig. 5A). Care should be exercised at this stage, to avoid damage of the superior longitudinal fasciculus, which runs above the insula, in the most lateral parts of the hemisphere (Fig. 5A). Türe et al. [53] recommend to begin dissection from the opening of superior temporal sulcus. Then arcuate and superior longitudinal fasciculi should be gradually delineated. The superior longitudinal fasciculus is located deep to the middle frontal gyrus, inferior parietal lobule, and middle temporal gyrus [53]. At this stage of the dissection, arcuate fasciculus may also be exposed (Fig. 5A). It is large arch-shaped fibre group that sweeps down into the temporal lobe. The arcuate fasciculus was considered to be the inferior part of the superior longitudinal fasciculus [23]; however, according to new Terminologia Neuroanatomica, it has been identified as a distinct entity [51].

At this stage, after the arcuate fasciculus is dissected away, long association fibres such as the inferior occipitofrontal fasciculus and uncinate fasciculus should be exposed (Fig. 5B, C). The inferior occip- 

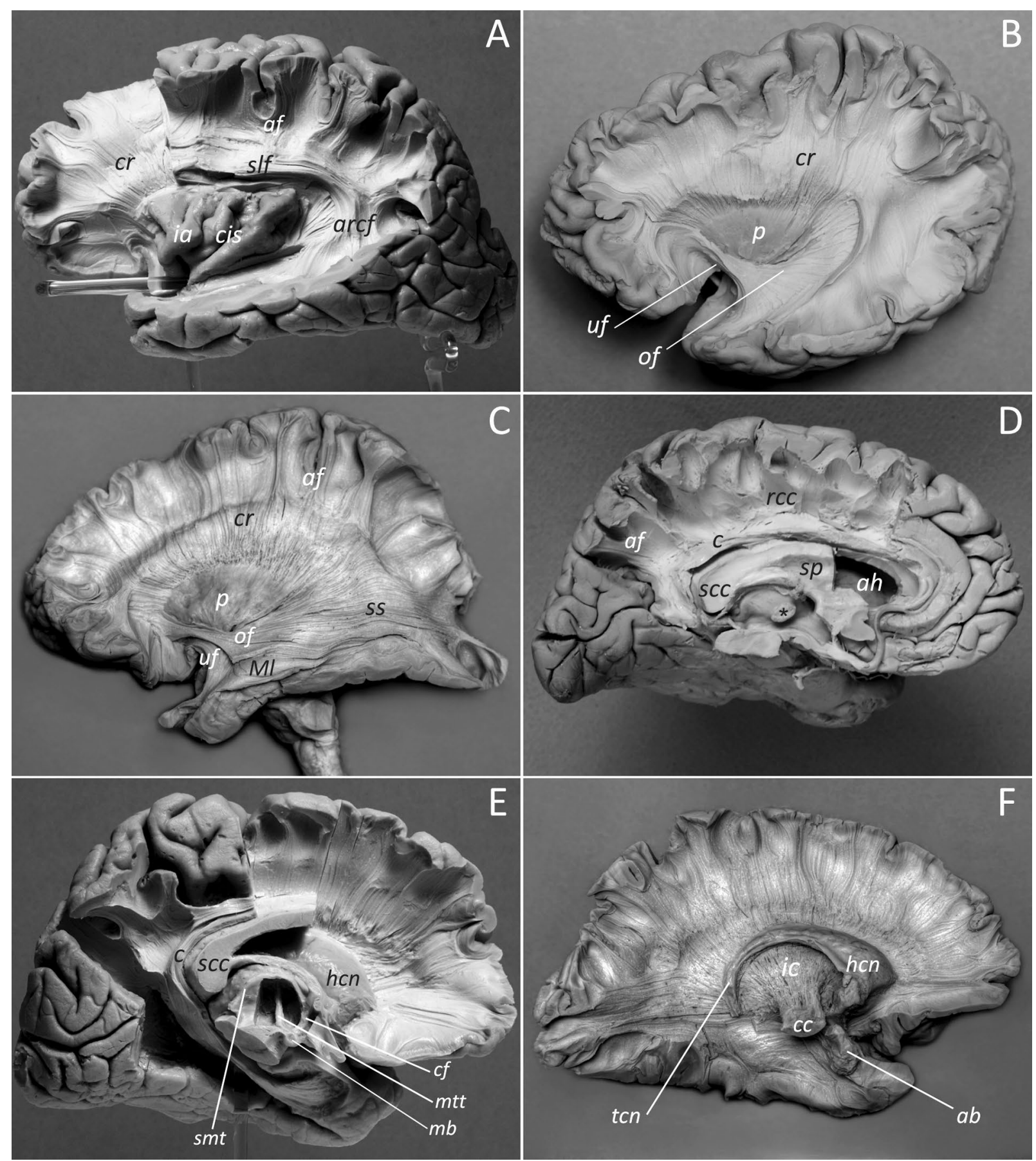

E
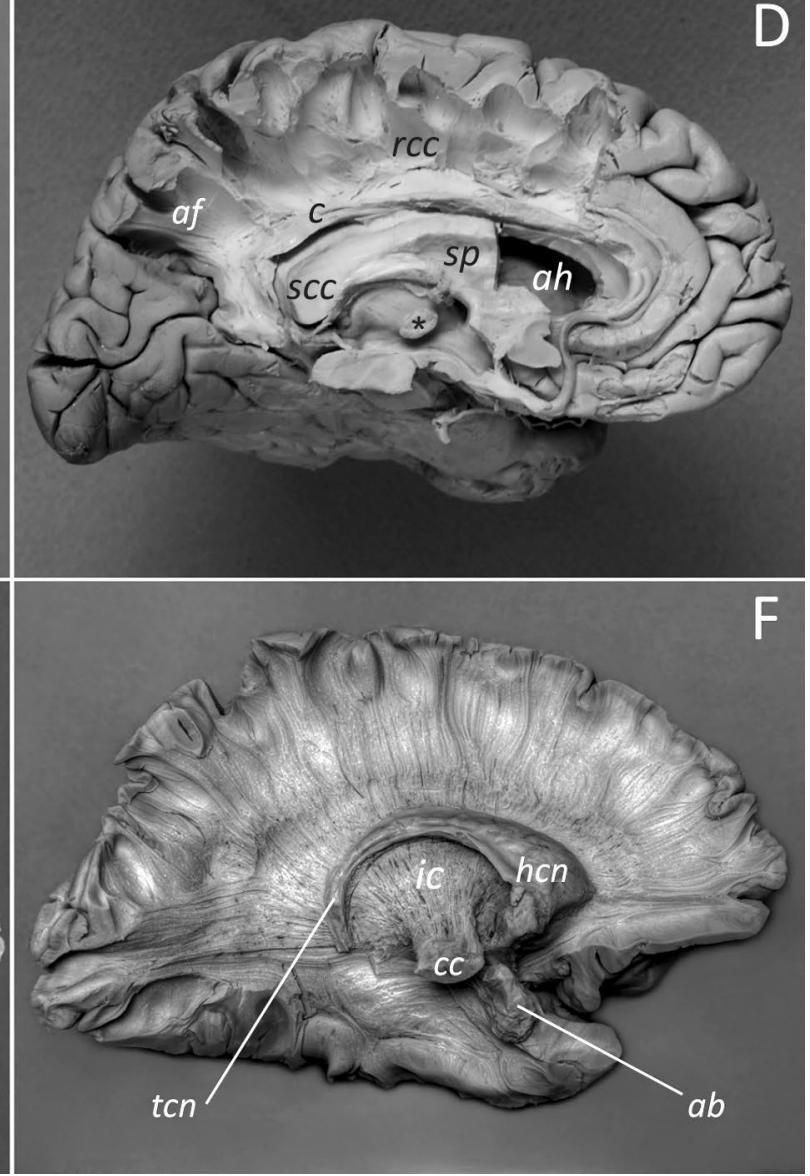

Figure 5. Specimens prepared by use of Klingler's method of brain dissection. A, B, C. A view on superolateral aspects of the left cerebral hemispheres; D, E, F. Medial aspects of the left hemispheres. A. Insular cortex, superior longitudinal fasciculus (slf) and arcuate fasciculus (arcf) were exposed; af — U fibres (arcuate fibres); ia — insular apex; cis — central insular sulcus; cr — corona radiate; $\mathbf{B}$. View on the corona radiata (cr) and the putamen (p). Uncinate fasciculus (uf) and inferior occipitofrontal fasciculus (of) were also exposed; C. Deep dissection of the superolateral surface of the left cerebral hemisphere. Sagittal stratum (ss) and Meyer's loop (MI) were shown; D. Cingulum (c) and radiation of corpus callosum ( $\mathrm{rcc}$ ) were exposed by blunt dissection. Anterior horn of the lateral ventricle (ah) was opened; scc - splenium of corpus callosum; sp - septum pellucidum; *interthalamic adhesion; E. Dissection of the mammillothalamic tract (mtt). The thalamus was partially removed up to the stria medullaris of thalamus (smt). The part of column of fornix (cf) which passes through grey matter was also exposed; mb - mammillary body; hcn — head of caudate nucleus; F. Deep dissection of the medial surface of the left cerebral hemisphere. Thalamus was removed to visualise the internal capsule (ic). Caudate nucleus with its head (hcn) and tail (tcn) was exposed. Inferior part of the tail of the caudate nucleus was not saved; cc — cerebral crus; ab — amygdaloid body. 
itofrontal fasciculus runs within the insula, temporal stem and sagittal stratum, while the uncinate fasciculus crosses the limen of the insula and connects the orbitofrontal cortex with the anterior part of the temporal lobe [33]. At this point, attention should be put to the course of particular projection fibres such as optic radiation (geniculocalcarine tract). The initial portion of the tract loops from the lateral geniculate body anteriorly and then twists posteriorly forming highly curved portion of the optic radiation referred to as Meyer's loop (Fig. 5C) [23]. After gentle removal of the insular cortex an access is obtained to alternating layers of white and grey matter, namely: extreme capsule, claustrum, external capsule and putamen. The extreme and external capsules should be removed with extreme care, as it is easy to damage the underlying grey matter structures. In order to dissect away the extreme or external capsule from the underlying grey matter, a small and shallow vertical incision may be made with a scalpel and then a thin probe with rounded edge may be inserted between the two layers to separate them. Removal of the external capsule reveals the lateral convex surface of the putamen (Fig. 5B, C). The stratigraphic dissection may be completed by the removal of the lentiform nucleus, which allows to visualize the continuity of the corona radiata with the internal capsule.

Dissection from the medial side should begin with peeling away the cortex of the cingulate gyrus to expose the cingulum (Fig 5D). The cingulum should be traced throughout its entire course. In the posterior direction, it sweeps down behind the splenium of the corpus callosum and ends within the parahippocampal gyrus (Fig. 5E). The exposure of the radiation of the corpus callosum may be performed by the removal of white matter fibres along the callosal sulcus. The medial part of the corpus callosum may be cut off and removed together with the septum pellucidum and fornix. However, various modifications of the procedure are possible at this stage. Removal of the front part of the corpus callosum provides insight into the lateral ventricle. Such a modification enables following boundaries of the body and anterior horn of the lateral ventricle (Fig. 5D, E). Careful dissection of the corpus callosum allows visualisation of the caudate nucleus (Fig. 5E, F). The tail of the caudate nucleus may be traced as far up to as the amygdaloid body. When the caudate nucleus is dissected away, the thalamic radiation comes to view [14,23]. Removal of the thalamus reveals the internal capsule and

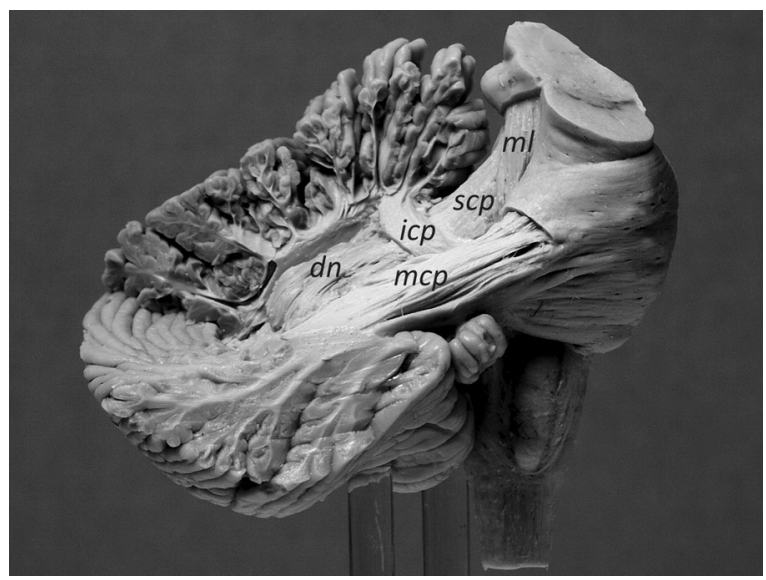

Figure 6. The dissection of the cerebellar peduncles. The relationships between the superior (scp) and inferior (icp) cerebellar peduncles can be studied. Part of the inferior cerebellar peduncle was removed to expose the dentate nucleus (dn); $\mathrm{mcp}$ - middle cerebellar peduncle; $\mathrm{ml}$ — medial lemniscus.

its continuity with the cerebral crus (Fig. 5F). While proceeding gently during the removal of thalamic grey matter, the covered part of the column of fornix and the mammillothalamic tract may be visualised (Fig. 5E). During the dissection of the medial surface of the cerebral hemisphere the anterior commissure may also be traced up to the anterior part of the temporal lobe.

Blunt dissection may also be particularly useful for tracing complex spatial relationships between the cerebellar peduncles (Fig. 6). However, some practice is needed to perform this procedure properly [23]. The superior cerebellar peduncle takes origin from the dentate nucleus and consists mainly of efferent fibres. The inferior cerebellar peduncle is a thick rope-like strand arising from the posterolateral surface of the medulla oblongata. The middle cerebellar peduncle, the largest one, extends between the base of pons and the cerebellum. While maintaining particular precision, selected intracerebellar nuclei may also be visualised in a gross-anatomic preparation [23]. An example of such a preparation, exposing the dentate nucleus, is presented in Figure 6.

\section{SIGNIFICANCE IN MEDICAL TRAINING AND CLINICAL PRACTISE}

In the first half of the $20^{\text {th }}$ century, the modern techniques of sectioning and staining of the brain tissue grew with popularity. Using those methods, however, is associated with the mental effort of reconstructing structures, after the observation of nu- 
merous sections in different planes [32]. This may especially discourage those who are taking their first steps in the field of neuroanatomy. Based on our teaching experience, students who had the opportunity to use specimens dissected by using Klingler's technique reported a better understanding of 3D brain structure. Evidence-based data should be collected in this context in the future. However, the study of Estevez et al. [16], on the predominance of 3D models over 2D ones, suggest that 3D physical modelling activity is an effective method for teaching spatial relationships of brain anatomy and may better prepare students for the visualisation of 3D neuroanatomy. In the study of Silva et al. [46] undergraduate neuroanatomy students used (observed and manipulated) specimens prepared by Klingler's technique. Research participants were asked to put particular attention to the organisation of white matter fibres and their relationships to the ventricular system and grey matter structures. They completed the survey concerning the usefulness of this material in their understanding of the 3D intrinsic anatomy of the brain white matter. The students reported an improvement in their understanding of the 3D intrinsic anatomy of the brain white matter [46].

With the development of knowledge regarding neurological and psychiatric disorders, new therapeutic options have emerged. Many of them require in-depth knowledge of the 3D topography of the central nervous system. It is noteworthy to mention new neuroimaging techniques $[1,3,4,14,17,18]$, deep brain stimulation [3], stereotactic neurosurgery or neuronavigation $[1,47]$, as well as detailed planning of neurosurgical procedures $[1,5,10,42-45$, 55]. In this context, the experience of fibre dissection aids in developing a spatial perception of pertinent anatomical structures, dissecting skills and it may be an important tool for neurosurgical training and neuroanatomical research $[1,14,33,46,53]$.

Mentions of Klingler's technique of fibres dissection appears in numerous recent publications in the field of neurosurgery and neuroimaging. Topographical knowledge is especially critical while performing disconnective callosotomies in epilepsy patients. In this context, Naets et al. [36] applied Klingler's fibre dissection method to perform "callosotopy." Cited authors examined leg motor connections illustrated by fibre dissection technique to study the course and topography of callosal fibres connecting the most medial part of the precentral gyrus. Verhaeghe et al. [55] dissected twenty hemispheres according to Klingler's technique of fibre dissection to reveal the extent of callosotomy required for successful posterior quadrant epilepsy surgery (a technique that allows to deafferent extensive areas of epileptogenic posterior cortex from the rest of the brain). Three-dimensional microsurgical and tractographic anatomy of the white matter was studied by Fernández-Miranda et al. [18]. The authors concluded that the fibre-dissection and diffusion-tensor magnetic resonance imaging techniques are reciprocally enriched in their practical use for diagnosis and surgical planning. De Benedictis et al. [12] examined the "temporo-parieto-occipital junction" using Klingler's dissection technique, tractography, and brain mapping. The cited study revealed that detailed information about the functional structure of the brain is mandatory to optimise surgical results and to minimise post-operative morbidity. Research on the sulcal and subcortical anatomy for the superior frontal transsulcal approach to the anterior ventricular system using anatomic dissections and diffusion tensor imaging tractography was conducted by Koutsarnakis et al. [27]. Sarubbo et al. [45], based on post mortem dissections and in vivo direct electrical mapping, conducted a detailed study on the course and the anatomic-functional relationships of the optic radiation for posterior temporal, inferior parietal and occipital resections. Those authors also drew attention to the preservation of inferior occipitofrontal fasciculus, which allows the preservation of the eloquent functions it subserves [45]. Nooij et al. [37] also stated that precise visualisation of the course of the visual pathways is relevant to prevent visual field deficits after neurosurgical resections.

Numerous detailed observations regarding white matter topography and spatial organisation have been made recently by using fibre dissection technique. A cadaveric study of the internal capsule based on fibre dissection was performed by Chowdhury et al. [9]. Peuskens et al. [40] described the anatomy of the anterior temporal lobe and the frontotemporal region demonstrated by fibre dissection. Vergani et al. [54], in turn, conducted a post mortem dissection study to examine intralobar fibres of the occipital lobe. Detailed anatomical descriptions of subcortical segmentation of the inferior longitudinal fasciculus were provided by Latini et al. [29]. Frontal terminations for the inferior occipitofrontal fasciculi were examined by Sarubbo et al. [44]. Segmentation of the 
cingulum bundle in the human brain was reported by Wu et al. [58].

The Klingler' method may also be used for qualitative and quantitative comparison of magnetic resonance tractography with dissection results [13, $15,62]$. Klingler's method was applied in the study evaluating the usefulness of photogrammetry of the human brain as a novel method for 3D quantitative exploration of the structural connectivity in neurosurgery and neurosciences [13]. Bozkurt et al. [5] used fibre dissection to study the microsurgical and tractographic anatomy of the supplementary motor area complex in humans. In this research, numerous connections and fibre bundles were revealed, such as the superior longitudinal fasciculus I, cingulum, claustrocortical fibres, callosal fibres, corticospinal tract, frontal aslant tract, and frontostriatal tract. Hau et al. [22], in turn, examined human uncinate fasciculus, its subcomponents, and asymmetries with stem-based tractography and microdissection validation. In this study, the stratigraphic microdissection using Klingler's method demonstrated five types of uncinate fibres according to their pattern, depth, and cortical terminations. Meola et al. [35] and Türe et al. [52] verified knowledge about superior occipitofrontal fasciculus in the human brain. Those authors concluded that two false continuations in fact generate the structure on the superolateral aspect of the caudate nucleus usually identified as the superior occipitofrontal fasciculus: first between superior thalamic peduncle and stria terminalis, and the second between stria terminalis and posterior thalamic peduncle. The anatomical fibre microdissection confirmed those findings. Thus, fibre dissection technique in connection with modern diagnostic and research methods allows to verify and deepen current knowledge in the field of neuroscience.

\section{CONCLUSIONS}

The fibre dissection technique may still be considered an excellent complementary research tool for neuroanatomical studies. Numerous detailed observations about the white matter topography and spatial organisation have been recently made by applying this method. Using this technique may also improve understanding of the 3D intrinsic structure of the brain, which is particularly important both in under- and postgraduate training in the field of neuroanatomy.

\section{REFERENCES}

1. Agrawal A, Kapfhammer JP, Kress A, et al. Josef Klingler's models of white matter tracts: influences on neuroanatomy, neurosurgery, and neuroimaging. Neurosurgery. 2011; 69(2): 238-52; discussion 252, doi: 10.1227/NEU.0b013e318214ab79, indexed in Pubmed: 21368687.

2. Arantes M, Arantes J, Ferreira MA. Tools and resources for neuroanatomy education: a systematic review. BMC Med Educ. 2018; 18(1): 94, doi: 10.1186/s12909-018-1210-6, indexed in Pubmed: 29724217.

3. Avecillas-Chasin JM, Rascón-Ramírez F, Barcia JA. Tractographical model of the cortico-basal ganglia and corticothalamic connections: Improving Our Understanding of Deep Brain Stimulation. Clin Anat. 2016; 29(4): 481-492, doi: 10.1002/ca.22689, indexed in Pubmed: 26779936.

4. Bertani GA, Bertulli L, Scola E, et al. Optic radiation diffusion tensor imaging tractography: an alternative and simple technique for the accurate detection of meyer's loop. World Neurosurg. 2018; 117: e42-e56, doi: 10.1016/j. wneu.2018.05.131, indexed in Pubmed: 29857218.

5. Bozkurt B, Yagmurlu K, Middlebrooks EH, et al. Microsurgical and tractographic anatomy of the supplementary motor area complex in humans. World Neurosurg. 2016; 95: 99-107, doi: 10.1016/j.wneu.2016.07.072, indexed in Pubmed: 27476690.

6. Böttger J, Schäfer A, Lohmann G, et al. Three-dimensional mean-shift edge bundling for the visualization of functional connectivity in the brain. IEEE Trans Vis Comput Graph. 2014; 20(3): 471-480, doi: 44E49295-068E-4AC0-989594C4713B93EC, indexed in Pubmed: 23959625.

7. Catani M. Principles of white matter organization. In: M Husain and JM. Schott (eds) Oxford Textbook of Cognitive Neurology and Dementia. Oxford University Pres Oxford Medicine Online. 2016, doi: 10.1093/ /med/9780199655946.001.0001.

8. Chang BS, Molnár Z. Practical neuroanatomy teaching in the 21st century. Ann Neurol. 2015; 77(6): 911-916, doi: 10.1002/ana.24405, indexed in Pubmed: 25810129.

9. Chowdhury F, Haque M, Sarkar M, et al. White fiber dissection of brain; the internal capsule: a cadaveric study. Turk Neurosurg. 2010; 20(3): 314-322, doi: 10.5137/10195149.JTN.3052-10.2, indexed in Pubmed: 20669103.

10. Corrivetti F, Froelich S, Mandonnet E. Endoscopic Approach of the Insula Through the Anterior Middle Temporal Gyrus: A Feasibility Study in the Laboratory. Oper Neurosurg (Hagerstown). 2017 [Epub ahead of print], doi: 10.1093/ /ons/opx128, indexed in Pubmed: 28973523.

11. da Carpi JB. Isagoge breves. Benedictus Hector, Bologna. $1523 ; 56$.

12. De Benedictis A, Duffau H, Paradiso B, et al. Anatomo-functional study of the temporo-parieto-occipital region: dissection, tractographic and brain mapping evidence from a neurosurgical perspective. J Anat. 2014; 225(2): 132-151, doi: 10.1111/joa.12204, indexed in Pubmed: 24975421.

13. De Benedictis A, Nocerino E, Menna F, et al. Photogrammetry of the human brain: a novel method for three-dimensional quantitative exploration of the structural connectivity in neurosurgery and neurosciences. World Neurosurg. 2018; 115: e279-e291, doi: 10.1016/j.wneu.2018.04.036, indexed in Pubmed: 29660551. 
14. de Castro I, Christoph Dd, dos Santos DP, et al. Internal structure of the cerebral hemispheres: an introduction of fiber dissection technique. Arq Neuropsiquiatr. 2005; 63(2A): 252-258, indexed in Pubmed: 16100971.

15. Dini LI, Vedolin LM, Bertholdo D, et al. Reproducibility of quantitative fiber tracking measurements in diffusion tensor imaging of frontal lobe tracts: A protocol based on the fiber dissection technique. Surg Neurol Int. 2013; 4: 51, doi: 10.4103/2152-7806.110508, indexed in Pubmed: 23646261.

16. Estevez ME, Lindgren KA, Bergethon PR. A novel three-dimensional tool for teaching human neuroanatomy. Anat Sci Educ. 2010; 3(6): 309-317, doi: 10.1002/ase.186, indexed in Pubmed: 20939033.

17. Feigl GC, Hiergeist W, Fellner C, et al. Magnetic resonance imaging diffusion tensor tractography: evaluation of anatomic accuracy of different fiber tracking software packages. World Neurosurg. 2014; 81(1): 144-150, doi: 10.1016/j.wneu.2013.01.004, indexed in Pubmed: 23295636.

18. Fernández-Miranda JC, Rhoton AL, Alvarez-Linera J, et al. Three-dimensional microsurgical and tractographic anatomy of the white matter of the human brain. Neurosurgery. 2008; 62(6 Suppl 3): 989-1026; discussion 1026, doi: 10.1227/01.neu.0000333767.05328.49, indexed in Pubmed: 18695585.

19. Finger S. Minds Behind the Brain: A History of the Pioneers and Their Discoveries. Oxford University Press, Oxford, New York 2000: 54-60.

20. Gross ChG. Brain, Vision, Memory. Tales in the History of Neuroscience. The MIT Press, London 1998: 1-41.

21. Haładaj R, Wysiadecki G, Polguj M, et al. Bilateral muscular slips between superior and inferior rectus muscles: case report with discussion on classification of accessory rectus muscles within the orbit. Surg Radiol Anat. 2018; 40(7): 855-862, doi: 10.1007/s00276-018-1976-6, indexed in Pubmed: 29368252.

22. Hau J, Sarubbo S, Houde JC, et al. Revisiting the human uncinate fasciculus, its subcomponents and asymmetries with stem-based tractography and microdissection validation. Brain Struct Funct. 2017; 222(4): 1645-1662, doi: 10.1007/s00429-016-1298-6, indexed in Pubmed: 27581617.

23. Heimer L. The Human Brain and Spinal Cord. Functional Neuroanatomy and Dissection Guide. Springer-Verlag, New York, Berlin, Heidelberg 1995: 59-118.

24. Ikeda M, Hossain MI, Zhou Li, et al. Histological detection of dynamic glial responses in the dysmyelinating Tabby-jimpy mutant brain. Anat Sci Int. 2018; 93(1): 119-127, doi: 10.1007/s12565-016-0383-5, indexed in Pubmed: 27888476.

25. Iturria-Medina Y. Anatomical brain networks on the prediction of abnormal brain states. Brain Connect. 2013; 3(1): 1-21, doi: 10.1089/brain.2012.0122, indexed in Pubmed: 23249224.

26. Jozefowicz RF. Neurophobia: the fear of neurology among medical students. Arch Neurol. 1994; 51(4): 328-329, indexed in Pubmed: 8155008.

27. Koutsarnakis C, Liakos F, Kalyvas AV, et al. The superior frontal transsulcal approach to the anterior ventricular system: exploring the sulcal and subcortical anato- my using anatomic dissections and diffusion tensor imaging tractography. World Neurosurg. 2017; 106: 339-354, doi: 10.1016/j.wneu.2017.06.161, indexed in Pubmed: 28698090.

28. Latini F, Hjortberg $M$, Aldskogius $H$, et al. The use of a cerebral perfusion and immersion-fixation process for subsequent white matter dissection. J Neurosci Methods. 2015; 253: 161-169, doi: 10.1016/j.jneumeth.2015.06.019, indexed in Pubmed: 26149289.

29. Latini F. New insights in the limbic modulation of visual inputs: the role of the inferior longitudinal fasciculus and the Li-Am bundle. Neurosurg Rev. 2015; 38(1): 179-189, doi: 10.1007/s10143-014-0583-1, indexed in Pubmed: 25323099.

30. Lohmann P, Piroth MD, Sellhaus B, et al. Correlation of Dynamic O-(2-[F]Fluoroethyl)-L-Tyrosine Positron Emission Tomography, Conventional Magnetic Resonance Imaging, and Whole-Brain Histopathology in a Pretreated Glioblastoma: A Postmortem Study. World Neurosurg. 2018; 119: e653-e660, doi: 10.1016/j.wneu.2018.07.232, indexed in Pubmed: 30077752.

31. Long J, Roberts DJH, Pickering JD. Preservation of cranial nerves during removal of the brain for an enhanced student experience in neuroanatomy classes. Clin Anat. 2014; 27(1): 20-24, doi: 10.1002/ca.22356, indexed in Pubmed: 24318012.

32. Ludwig E, Klingler J. Atlas cerebri humani. S. Karger, Basel, New York 1956: 15-20.

33. Martino J, De Witt Hamer PC, Vergani F, et al. Cortex-sparing fiber dissection: an improved method for the study of white matter anatomy in the human brain. J Anat. 2011; 219(4): 531-541, doi: 10.1111/j.14697580.2011.01414.x, indexed in Pubmed: 21767263.

34. Mayo HM. A series of engravings intended to illustrate the structure of the brain and spinal cord in man. Burgess and Hill, London 1827

35. Meola A, Comert A, Yeh FC, et al. The controversial existence of the human superior fronto-occipital fasciculus: Connectome-based tractographic study with microdissection validation. Hum Brain Mapp. 2015; 36(12): 4964-4971, doi: 10.1002/hbm.22990, indexed in Pubmed: 26435158.

36. Naets W, Van Loon J, Paglioli E, et al. Callosotopy: leg motor connections illustrated by fiber dissection. Brain Struct Funct. 2017; 222(1): 661-667, doi: 10.1007/s00429015-1167-8, indexed in Pubmed: 26666531.

37. Nooij RP, Hoving EW, van Hulzen AL, et al. Preservation of the optic radiations based on comparative analysis of diffusion tensor imaging tractography and anatomical dissection. Front Neuroanat. 2015; 9: 96, doi: 10.3389/ fnana.2015.00096, indexed in Pubmed: 26300739.

38. Pascalau R, Popa Stănilă R, Sfrângeu $S$, et al. Anatomy of the limbic white matter tracts as revealed by fiber dissection and Tractography. World Neurosurg. 2018; 113: e672-e689, doi: 10.1016/j.wneu.2018.02.121, indexed in Pubmed: 29501514.

39. Persaud TV, Loukas M, Tubbs RSA. A history of Human Anatomy. Second Edition. Charles C Thomas Publisher, Ltd., Springfield, IL, 2014: 12.

40. Peuskens D, van Loon J, Van Calenbergh F, et al. Anatomy of the anterior temporal lobe and the fron- 
totemporal region demonstrated by fiber dissection. Neurosurgery. 2004; 55(5): 1174-1184, doi: 10.1227/01. neu.0000140843.62311.24, indexed in Pubmed: 15509324.

41. Poliakov AV, Albright E, Hinshaw KP, et al. Server-based approach to web visualization of integrated three-dimensional brain imaging data. J Am Med Inform Assoc. 2005; 12(2): 140-151, doi: 10.1197/jamia.M1671, indexed in Pubmed: 15561787.

42. Rhoton A. The supratentorial cranial space: microsurgical anatomy and surgical approaches. Neurosurgery. 2002; 51(suppl_4), doi: 10.1097/00006123-200210001-00001.

43. Sarubbo S, Basso G, Chioffi F, et al. Technical, anatomical, and functional study after removal of a symptomatic cavernous angioma located in deep wernicke's territories with cortico-subcortical awake mapping. Case Rep Neurol Med. 2013; 2013: 835029, doi: 10.1155/2013/835029, indexed in Pubmed: 23864972.

44. Sarubbo S, De Benedictis A, Maldonado IL, et al. Frontal terminations for the inferior fronto-occipital fascicle: anatomical dissection, DTI study and functional considerations on a multi-component bundle. Brain Struct Funct. 2013; 218(1): 21-37, doi: 10.1007/s00429-011-0372-3, indexed in Pubmed: 22200882.

45. Sarubbo S, De Benedictis A, Milani $P$, et al. The course and the anatomo-functional relationships of the optic radiation: a combined study with 'post mortem' dissections and 'in vivo' direct electrical mapping. J Anat. 2015; 226(1): 47-59, doi: 10.1111/joa.12254, indexed in Pubmed: 25402811.

46. Silva SM, Andrade JP. Neuroanatomy: The added value of the Klingler method. Ann Anat. 2016; 208: 187-193, doi: 10.1016/j.aanat.2016.06.002, indexed in Pubmed: 27329122.

47. Skadorwa T, Kunicki J, Nauman P, et al. Image-guided dissection of human white matter tracts as a new method of modern neuroanatomical training. Folia Morphol. 2009; 68(3): 135-139, indexed in Pubmed: 19722156.

48. Sporns O, Chialvo DR, Kaiser M, et al. Organization, development and function of complex brain networks. Trends Cogn Sci. 2004; 8(9): 418-425, doi: 10.1016/j. tics.2004.07.008, indexed in Pubmed: 15350243.

49. Swanson L. Neuroanatomical Terminology. A Lexicon of Classical Origins and Historical Foundations. Oxford University Press, Oxford, New York 2014.

50. Szmuda T, Rogowska M, Słoniewski P, et al. Frontal aslant tract projections to the inferior frontal gyrus. Folia Morphol. 2017; 76(4): 574-581, doi: 10.5603/FM.a2017.0039, indexed in Pubmed: 28553860.

51. Ten Donkelaar HJ, Broman J, Neumann PE, et al. Towards a Terminologia Neuroanatomica. Clin Anat. 2017; 30(2): 145-155, doi: 10.1002/ca.22809, indexed in Pubmed: 27910135.

52. Türe U, Yaşargil MG, Pait TG. Is there a superior occipitofrontal fasciculus? A microsurgical anatomic study. Neurosurgery. 1997; 40(6): 1226-1232, doi: 10.1097/00006123199706000-00022, indexed in Pubmed: 9179896.

53. Türe $U$, Yaşargil MG, Friedman $A H$, et al. Fiber dissection technique: lateral aspect of the brain. Neurosurgery. 2000; 47(2): 417-26; discussion 426, doi: 10.1097/00006123200008000-00028, indexed in Pubmed: 10942015.
54. Vergani F, Mahmood S, Morris CM, et al. Intralobar fibres of the occipital lobe: a post mortem dissection study. Cortex. 2014; 56: 145-156, doi: 10.1016/j.cortex.2014.03.002, indexed in Pubmed: 24768339.

55. Verhaeghe A, Decramer T, Naets W, et al. Posterior Quadrant Disconnection: A Fiber Dissection Study. Oper Neurosurg (Hagerstown). 2018; 14(1): 45-50, doi: 10.1093/ ons/opx060, indexed in Pubmed: 29253283.

56. Vesalius A. Andreae Vesalii Bruxellensis, scholae medicorum Patauinae professoris De humani corporis fabrica libri septem. Ex officina Joannis Oporini, Basel 1543: 605-609.

57. Willis T. Dr. Willis's Practice of physick, being the whole works of that renowned and famous physician: containing these eleven several treatises, viz. I. Of fermentation. II. Of feavers. III. Of urines. IV. Of the accension of the blood. V. Of musculary motion. VI. Of the anatomy of the brain. VII. Of the description and use of the nerves. VIII. Of convulsive diseases. IX. Pharmaceutice rationalis, the first and second part. X. Of the scurvy. XI. Two discourses concerning the soul of brutes. (...) With forty copper plates / The Pharmaceutice new translated [as also the remainder, by Samuel Pordage], and the whole carefully corrected. Printed for T. Dring, C. Harper, and J. Leigh, London 1684.

58. Wu Y, Sun D, Wang Y, et al. Segmentation of the cingulum bundle in the human brain: a new perspective based on DSI tractography and fiber dissection study. Front Neuroanat. 2016; 10: 84, doi: 10.3389/fnana.2016.00084, indexed in Pubmed: 27656132.

59. Wysiadecki G, Polguj M, Topol M. An unusual variant of the abducens nerve duplication with two nerve trunks merging within the orbit: a case report with comments on developmental background. Surg Radiol Anat. 2016; 38(5): 625-629, doi: 10.1007/s00276-015-1573-x, indexed in Pubmed: 26501961.

60. Wysiadecki G, Małkiewicz A, Rożniecki J, et al. Anatomical variations of the insular gyri: A morphological study and proposal of unified classification. Clin Anat. 2018; 31(3): 347-356, doi: 10.1002/ca.23060, indexed in Pubmed: 29411429 .

61. Wysiadecki G, Haładaj R, Polguj M, et al. Bilateral extensive ossification of the posterior petroclinoid ligament: an anatomical case report and literature review. J Neurol Surg A Cent Eur Neurosurg. 2019; 80(2): 122-126, doi: 10.1055/ /s-0038-1666782, indexed in Pubmed: 30060260.

62. Zemmoura I, Serres B, Andersson F, et al. FIBRASCAN: a novel method for 3D white matter tract reconstruction in MR space from cadaveric dissection. Neuroimage. 2014; 103: 106-118, doi: 10.1016/j.neuroimage.2014.09.016, indexed in Pubmed: 25234114.

63. Zemmoura I, Blanchard E, Raynal PI, et al. How Klingler's dissection permits exploration of brain structural connectivity? An electron microscopy study of human white matter. Brain Struct Funct. 2016; 221(5): 2477-2486, doi: 10.1007/s00429-015-1050-7, indexed in Pubmed: 25905864.

64. Zhang J, Tian L, Zhang Li, et al. Relationship between white matter integrity and post-traumatic cognitive deficits: a systematic review and meta-analysis. J Neurol Neurosurg Psychiatry. 2019; 90(1): 98-107, doi: 10.1136/jnnp-2017317691, indexed in Pubmed: 30072375. 